\title{
ANALISIS CONJOINT PREFERENSI KONSUMEN TERHADAP KOMBINASI FITUR PRODUK MOTOR BEKAS BERDASARKAN SEGMEN GENDER DI JAMBI
}

\author{
Apriyanti \\ HIT Corporation, Gandaria Tower $7^{\text {th }}$ floor, Unit IJ \\ Jln. K.H. M. Syafi'I Hadzami No.8, Gandaria, Kebayoran Lama, Jakarta Selatan 12240 \\ yanti@hitcorporation.com; aphre_yanti@yahoo.com
}

\begin{abstract}
The purpose of this study is to determine consumer preferences for product attributes of used motorcycles. It is because motorcycles have so many variants that make consumers confused in choosing the products. Therefore, company should know what is required by the consumer to distinguish between men and women. This study used Cochrant $Q$ Test and Conjoint Analysis aiming to evaluate the characteristics of the motorcycle product attributes considered by consumers when buying a used motorcycle. The results of this study indicate, from 13 attributes considered by consumers to buy a used motorcycle, 6 considered the most important attribute is price, design, color, safety, fuel efficiency, and durability of the motorcycle. Men desired a combination of motorcycle price 5-7 million, classical design, having security alarm, dominant color, economic fuel, and durability of the body. As for women is a combination of motorcycle price <5 million, classical design, having security alarm, dominant color, economic fuel, and durability of the body.
\end{abstract}

Keywords: product attributes, cochran $Q$ tes, conjoint analysis, card stimuli, combination of product attributes

\begin{abstract}
ABSTRAK
Tujuan dari penelitian ini adalah untuk mengetahui preferensi konsumen terhadap atribut produk sepeda motor bekas. Begitu banyaknya varian sepeda motor membuat konsumen bingung dalam memilih produk. Oleh sebab itu, perusahaan harus tahu apa yang diinginkan oleh konsumen yang dibedakan antara lakilaki dan perempuan. Penelitian ini menggunakan metode Cochrant $Q$ Test dan Conjoint Analysis yang bertujuan untuk mengevalusi karakteristik atribut produk sepeda motor yang menjadi pertimbangan konsumen ketika membeli sepeda motor bekas. Hasil dari penelitian menunjukkan, dari 13 atribut yang menjadi pertimbangan konsumen dalam membeli sepeda motor bekas, 6 atribut yang dinilai paling penting, yaitu: harga, desain, warna, keamanan, keiritan bahan bakar, dan daya tahan sepeda motor. Bagi laki-laki kombinasi yang diinginkan adalah harga motor 5-7 juta, desain motor yang klasik, keamanan motor menggunakan alarm, warna motor dominan warna, bahan bakar irit, dan daya tahan bodi motor. Sedangkan bagi perempuan adalah kombinasi harga motor <5juta, desain motor yang klasik, keamanan motor menggunakan alarm, warna motor dominan warna, bahan bakar yang irit, dan daya tahan bodi motor.
\end{abstract}

Kata kunci: atribut produk, cochran Q test, conjoint analysis, kartu stimuli, kombinasi atribut produk 


\section{PENDAHULUAN}

Dewasa ini kebutuhan akan transportasi memiliki peranan sangat penting. Banyaknya aktivitas pekerjaan menjadikan masyarakat sangat membutuhkan sarana transportasi. Salah satu alat transportasi yang banyak dikenal adalah sepeda motor. Asosiasi Industri Sepeda Motor Indonesia (AISI) mencatat penjualan sepeda motor mencapai 649.983 unit pada Januari 2013 (Liputan6, 2013). Angka ini sedikit lebih rendah dibandingkan dengan total penjualan pada Januari 2012, yaitu 652.601 unit (Popo, 2013).

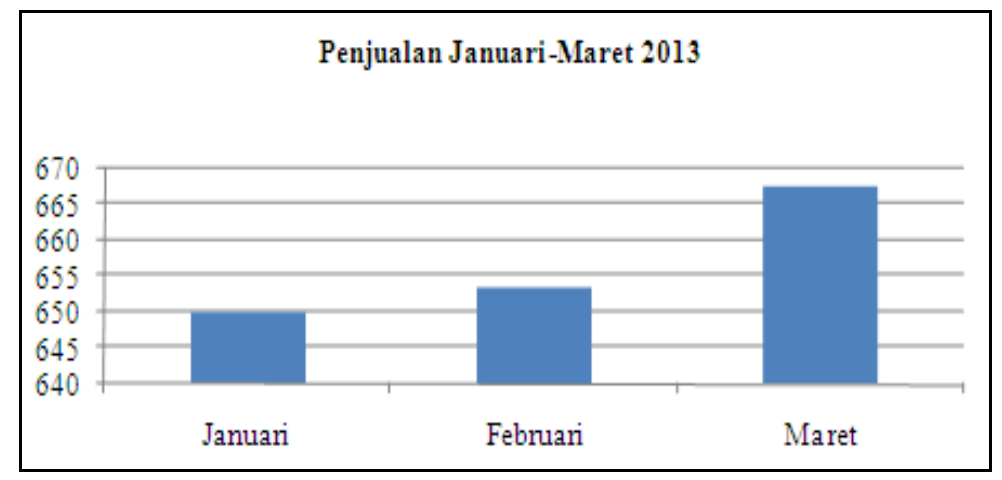

Gambar 1 Penjualan Januari - Maret 2013

(Asosiasi Industri Sepeda Motor Indonesia (AISI))

Besarnya kebutuhan akan sepeda motor tersebut meningkatkan permintaan masyarakat terhadap sepeda motor bekas. CV Dua Bersaudara adalah salah satu distributor sepeda motor bekas yang ada di kabupaten Tanjung Jabung Barat, Jambi. Menurut CV Dua Bersaudara, saat ini, khususnya di daerah Jambi, merek Yamaha menguasai pasar sepeda motor. Ini disebabkan berbagai alasan dari masyarakat mulai dari harga yang bersaing, sparepart yang mudah ditemukan, kualitas yang baik, harga jual kembali yang tinggi, desain yang modern, dan lainnya sehingga Yamaha menjadi pilihan masyarakat sekitar untuk menjadi primadona kendaraan di daerah Jambi. Selain itu, fitur-fitur sepeda motor tersebut akan berbeda jika dilihat dari sudut pandang gender laki-laki dibandingkan dengan perempuan.

\section{Landasan Teori}

Pemilihan atau preferensi terhadap sepeda motor bekas oleh konsumen akan mempertimbangkan berbagai fitur yang ditawarkan. Menurut Chaplin (2002), preferensi adalah suatu sikap yang lebih menyukai sesuatu benda daripada benda lainnya. Lebih lanjut menurutnya, penilaian preferensi adalah teknik penelitian dengan menyajikan dua atau lebih perangsang yang harus dipilih subjek yang dapat diukur lewat tes verbal atau lisan.

Menurut Aaker (2003), dalam menentukan pilihannya untuk membeli suatu produk, konsumen sering mempertimbangkan berbagai faktor. Bagi konsumen faktor tersebut bersifat trade-off yang membuat konsumen serba salah. Misalnya antara harga dan kualitas, mana yang harus dipilih, haruskah memilih harga rendah dengan kualitas rendah atau harga tinggi dengan kualitas prima tergantung dari preferensi konsumen. Kemudian menurut Simamora (2003), faktor-faktor pertimbangan yang berhubungan dengan produk adalah kualitas, fitur, dan desain. Fitur atau atribut produk meliputi dimensi-dimensi produk, juga menyangkut apa saja yang dipertimbangkan dalam pengambilan keputusan untuk membeli, menonton, memerhatikan suatu produk, seperti harga, ketersediaan produk, merek, harga jual kembali, ketersediaan suku cadang, layanan purnajual, dll. 
(Haryadi, 2007). Sebuah produk dapat ditawarkan dengan beraneka macam fitur. Perusahaan dapat menciptakan model dengan tingkat yang lebih tinggi dengan menambah beberapa fitur. Fitur adalah alat bersaing untuk membedakan produk perusahaan dari produk pesaing (Kotler \& Armstrong, 2004).

Secara garis besar pembeli sepeda motor dapat disegmentasi berdasarkan gender. Fakih (2006) mengemukakan bahwa gender merupakan suatu sifat yang melekat pada kaum laki-laki maupun perempuan yang dikonstruksikan secara sosial maupun kultural. Perubahan ciri dan sifat-sifat yang terjadi dari waktu ke waktu dan dari tempat ke tempat lainnya disebut konsep gender. Gender atau jenis kelamin merupakan suatu alat untuk membedakan mana perempuan dan mana laki-laki. Dari jenis kelamin pula dapat dilihat sikap yang memengaruhi preferensi ataupun memilih atribut-atribut produk yang menurut mereka penting. Seperti yang diketahui, laki-laki dan perempuan memiliki pemikiran atau persepsi yang berbeda.

Untuk mengetahui kombinasi fitur sepeda motor, maka perlu digunakan analisis statistik yang tepat, yaitu analisis conjoint. Menurut Hair et al. (2005):

"Conjoint analysis is a multivariate technique developed specifically to understand how respondents develop preferences for any type of object (products, services, or ideas). It is based on the simple premise that consumers evaluate the value of an object (real or hypothetical) by combining the seperate amounts of value provided by each attribute."

Atau, dengan kata lain, analisis conjoint adalah salah satu teknik multivarian yang khusus digunakan untuk mengetahui bagaimana responden mengembangkan preferensinya terhadap semua jenis objek (produk, jasa, atau ide). Analisis ini berdasarkan alasan yang sederhana karena konsumen dapat mengevaluasi nilai-nilai dari produk tersebut (nyata atau hipotesis) melalui kombinasi beberapa nilai yang terpisah-pisah dari setiap atribut.

\section{METODE}

Penelitian ini menggunakan dua jenis data sumber. Data Primer, yaitu data yang didapatkan secara langsung dari konsumen CV Dua Bersaudara sebagai responden. Kuesioner disebarkan untuk mengukur atribut apa yang dianggap penting oleh konsumen dan atribut produk mana yang dalam memilih kendaraan roda dua menjadi keinginan konsumen. Data sekunder, yaitu data yang didapat dari CV Dua Bersaudara (data profil perusahaan) dan data referensi dari artikel jurnal, Internet, dan buku yang menunjang penelitian.

Teknik pengambilan sampel yang digunakan pada penelitian ini adalah populasi. Populasi, menurut Riduwan dan Kuncoro (2007), adalah keseluruhan dari karakteristik atau unit hasil pengukuran yang menjadi objek penelitian; atau, populasi merupakan objek atau subjek yang berada pada suatu wilayah dan memenuhi syarat tertentu yang berkaitan dengan masalah penelitian. Berdasarkan hasil wawancara dengan pemilik dan manajer bidang administrasi, disebutkan rata-rata populasi konsumen pertahun adalah 160 orang. Dengan demikian jumlah ini memenuhi syarat digunakannya analisis conjoint. Menurut Hair et al (2006) kecukupan sampel terbaik untuk conjoint analysis adalah minimal 60 responden.

Populasi dalam penelitian ini dibagi menjadi segmen perempuan dan laki-laki. Dalam penelitian ini ingin diketahui kriteria bagaimana yang diinginkan oleh perempuan dan bagaimana yang diinginkan laki-laki. Berdasarkan hasil kuesioner profil responden mengenai jenis kelamin dari 100 orang responden, maka diperoleh data sebagai berikut. Responden yang berjenis kelamin laki-laki sebanyak 87 orang $(58 \%)$ dan sisanya adalah perempuan yaitu 63 orang $(42 \%)$. 
Metode yang digunakan merupakan jenis statistik deskriptif, yaitu dengan menggunakan Analisis Cochran Q Test dan Analisis Konjoin (Conjoint Analysis). Penggunaan metode Cochran Q Test and Conjoint Analysis dimaksudkan untuk mengetahui preferensi pembeli dalam memilih kendaraan. Hasil analisis dapat digunakan perusahaan untuk penyediaan produk yang sesuai dengan konsumennya (Aryanto \& Sentosa, 2012).

\section{HASIL DAN PEMBAHASAN}

Berdasarkan dari hasil pengujian menggunakan metode Cochran $Q$ Test, diketahui bahwa atribut-atribut yang menjadi pertimbangan konsumen dalam memilih produk kendaraan roda dua adalah harga, desain, warna, keiiritan bahan bakar, daya tahan, dan keamanan.

Berdasarkan hasil pengujian menggunakan conjoint analysis, diketahui preferensi konsumen secara keseluruhan berdasarkan data laki-laki dan perempuan diketahui bahwa atribut harga dengan tingkat kepentingan sebesar $20.608 \%$, secara umum responden menyukai harga motor < 5juta dibandingkan dengan harga 5-7juta atau >7juta. Untuk atribut desain dengan tingkat kepentingan sebesar $20.090 \%$, secara umum responden lebih menyukai desain klasik dibandingkan dengan desain bebek atau sporti. Untuk atribut keamanan motor dengan tingkat kepentingan 19.979\%, secara umum responden menyukai keamanan motor dengan menggunakan alarm dibandingkan dengan kunci pengaman atau GPS tracker. Untuk atribut warna dengan tingkat kepentingan sebesar $18.223 \%$, secara umum responden menyukai warna dominan silver dibandingkan warna dominan hitam atau dominan warna. Untuk atribut bahan bakar dengan tingkat kepentingan $10.952 \%$, secara umum responden menyukai bahan bakar yang irit dibandingkan dengan bahan bakar yang boros. Untuk atribut daya tahan dengan tingkat kepentingan $10.149 \%$, secara umum responden menyukai daya tahan bodi dibandingkan daya tahan mesin.

Berdasarkan hasil pengujian menggunakan conjoint analysis, diketahui preferensi konsumen berdasarkan data laki-laki, bahwa atribut harga dengan tingkat kepentingan sebesar $20.415 \%$, secara umum responden menyukai harga motor 5-7juta dibandingkan dengan harga $<5$ juta atau $>7$ juta. Untuk atribut desain dengan tingkat kepentingan sebesar $20.186 \%$, secara umum responden lebih menyukai desain klasik dibandingkan dengan desain bebek atau sporti. Untuk atribut keamanan motor dengan tingkat kepentingan $20.098 \%$, secara umum responden menyukai keamanan motor dengan menggunakan alarm dibandingkan dengan kunci pengaman atau GPS tracker. Untuk atribut warna dengan tingkat kepentingan sebesar $18.135 \%$, secara umum responden menyukai warna dominan hitam dibandingkan warna dominan silver atau dominan warna. Untuk atribut bahan bakar dengan tingkat kepentingan $11.311 \%$, secara umum responden menyukai bahan bakar yang irit dibandingkan dengan bahan bakar yang boros. Untuk atribut daya tahan dengan tingkat kepentingan $9.855 \%$, secara umum responden menyukai daya tahan bodi dibandingkan daya tahan mesin.

Berdasarkan hasil pengujian menggunakan conjoint analysis, diketahui preferensi konsumen berdasarkan data perempuan, bahwa atribut harga dengan tingkat kepentingan sebesar $20.874 \%$, secara umum responden menyukai harga motor < 5juta dibandingkan dengan harga 5-7juta atau >7juta. Untuk atribut keamanan motor dengan tingkat kepentingan $19.814 \%$, secara umum responden menyukai keamanan motor dengan menggunakan alarm, dibandingkan dengan kunci pengaman atau GPS tracker. Untuk atribut desain dengan tingkat kepentingan sebesar 19.957\%, secara umum responden lebih menyukai desain klasik dibandingkan dengan desain bebek atau sporti. Untuk atribut warna dengan tingkat kepentingan sebesar $18.344 \%$, secara umum responden menyukai warna dominan hitam dibandingkan warna dominan silver atau dominan warna. Untuk atribut daya tahan dengan tingkat kepentingan $10.555 \%$, secara umum responden menyukai daya tahan bodi dibandingkan daya tahan mesin. Untuk atribut bahan bakar dengan tingkat kepentingan $10.457 \%$, secara umum responden menyukai bahan bakar yang irit, dibandingkan dengan bahan bakar yang boros. 
Tabel 1 Perbedaan Preferensi pada Kombinasi Atribut Produk Sepeda Motor Yamaha Bekas

\begin{tabular}{|c|c|c|c|c|c|}
\hline \multirow{2}{*}{ No } & \multirow{2}{*}{ Atribut (Factor) } & \multirow{2}{*}{$\frac{\text { Laki-laki }}{\text { Taraf (Level) Atribut }}$} & \multicolumn{3}{|c|}{ Perempuan } \\
\hline & & & Utilitas & Taraf (Level) Atribut & Utilitas \\
\hline \multirow{3}{*}{1.} & \multirow{3}{*}{ Harga motor } & $<5$ juta & 0.079 & $<5$ juta & 0.324 \\
\hline & & 5juta-7juta & 0.086 & 5juta-7juta & -0.279 \\
\hline & & $>7$ juta & -.164 & $>7$ juta & -0.045 \\
\hline \multirow{3}{*}{2.} & \multirow{3}{*}{ Desain motor } & Clasic & 0.330 & Clasic & 0.581 \\
\hline & & Bebek & -0.205 & Bebek & -0.401 \\
\hline & & Sporty & -0.125 & Sporty & -0.179 \\
\hline \multirow{3}{*}{3.} & \multirow{3}{*}{ Warna motor } & Dominan hitam & 0.266 & Dominan hitam & 0.176 \\
\hline & & Dominan silver & -0.344 & Dominan silver & -0.201 \\
\hline & & Dominan warna & 0.078 & Dominan warna & 0.025 \\
\hline \multirow{2}{*}{4.} & \multirow{2}{*}{ Bahan bakar } & Irit & 0.105 & Irit & 0.213 \\
\hline & & Boros & -0.105 & Boros & -0.213 \\
\hline \multirow{2}{*}{5.} & \multirow{2}{*}{ Daya tahan motor } & Body & 0.348 & Body & 0.364 \\
\hline & & Mesin & -0.348 & Mesin & -0.364 \\
\hline \multirow{2}{*}{6.} & \multirow{2}{*}{ Keamanan motor } & Kunci pengaman & -0.082 & Kunci pengaman & -0.216 \\
\hline & & Alaram & 0.232 & Alaram & 0.570 \\
\hline
\end{tabular}

Sumber: Hasil Pengolahan Data (2013)

\section{SIMPULAN}

Simpulan dari hasil penelitian tentang analisis preferensi konsumen tentang produk sepeda motor adalah sebagai berikut. Pertama, dari hasil analisis Cochran $Q$ Test atribut produk yang memengaruhi preferensi konsumen adalah harga, desain, warna, keiritan bahan bakar, daya tahan, dan keamanan. Kedua, dari hasil Conjoint Analysis atribut produk yang dianggap penting oleh konsumen sesuai dengan preferensi adalah atribut harga dengan nilai $20.608 \%$, atribut desain dengan nilai $20.090 \%$, atribut keamanan dengan nilai $19.979 \%$, atribut warna dengan nilai $18.223 \%$, atribut bahan bakar dengan nilai 10.952 , dan atribut daya tahan dengan nilai $10.149 \%$. Kemudian ketiga, dari hasil Conjoint Analysis preferensi produk sepeda motor berdasarkan jenis kelamin laki-laki adalah kombinasi harga motor 5-7juta, desain motor yang klasik, keamanan motor menggunakan alarm, warna motor dominan warna, bahan bakar yang irit, dan daya tahan bodi motor. Lalu kelima, sedangankan preferensi produk sepeda motor berdasarkan jenis kelamin perempuan adalah kombinasi harga motor <5juta, desain motor yang klasik, keamanan motor menggunakan alarm, warna motor dominan warna, bahan bakar yang irit, dan daya tahan bodi motor.

Saran-saran yang dapat berikan sebagai hasil dari analisis preferensi konsumen pada kombinasi fitur motor bekas di CV Dua Bersaudara melaui penelitian ini adalah sebagai berikut. Pertama, fitur atau atribut harga merupakan atribut yang memiliki tingkat kepentingan yang tinggi di antara fitu-fitur yang lain. Oleh karena itu, disarankan pada perusahaan untuk lebih memerhatikan atribut yang dianggap paling penting oleh konsumen dalam mengembangkan produk sesuai dengan target yang dicapai. Kedua, perusahaan dapat menawarkan sepeda motor dengan harga 5juta-7juta, dengan desain klasik, berwarna dominan hitam, bahan bakar yang irit, daya tahan bodi, dan keamanan motor yang menggunakan alarm untuk calon konsumen laki-laki. Ketiga, perusahaan dapat menawarkan sepeda motor dengan harga <5juta, dengan desain klasik, berwarna dominan warna, bahan bakar yang irit, daya tahan bodi, dan keamanan motor yang menggunakan alarm untuk calon konsumen perempuan. Perusahaan juga disarankan agar dapat melakukan pengamatan secara berkala tentang preferensi konsumen tersebut dengan menggunakan metode conjoint. 


\section{DAFTAR PUSTAKA}

Aaker, D. A. (2003). Marketing Research. US: John Wiley \& Sons.

Aryanto, R. \& Sentosa, H. (2012). Student preferences toward automobile multiattributes: a conjoint analysis. Proceeding International Conference on Management, Hospitality \& Toutrism, and Accounting. Jakarta.

Chaplin, J. P. (2002). Kamus Lengkap Psikologi. Terjemahan dr. Kartini Kartono. Edisi Kelima. Jakarta: Raja Grafindo Persada.

Fakih, M. (2006). Analisis Gender dan Transformasi Sosial. Yogyakarta: Pustaka Pelajar.

Hair Jr., J. F., et al., (2006). Multivariate Data Analysis. 6th Edition. New Jersey: Prentice-Hal.

Haryadi, A. (2007). Kiat Membuat Promosi Penjualan Secara Efektif dan Terencana. Edisi. Kedua. Jakrta: Elex Media Komputindo.

Kotler, P. \& Armstrong, G. (2004). Principles of Marketing. 10th Edition. New Jersey: Pearson Prentice Hall.

Liputan6. (2013, 13 Februari). Penjualan Motor Capai 649.983 Unit dalam Sebulan. Diakses dari http://bisnis.liputan6.com/read/510400/penjualan-motor-capai-649983-unit-dalam-sebulan.

Popo. (2013, 11 Februari). Penjualan Sepeda Motor Januari 2013, Turun Bila Dibandingkan 2012. Diakses dari http://motor.otomotifnet.com/read/2013/02/11/338321/30/9/Penjualan-SepedaMotor-Januari-2013-Turun-Bila-Dibandingkan-2012.

Riduwan \& Kuncoro, E. A. (2007). Cara Menggunakan dan Memakai Analisis Jalur. Cetakan Pertama. Penerbit Alfabeta, Bandung.

Simamora, B. (2003). Panduan Riset Perilaku Konsumen. Jakarta: Gramedia Pustaka Utama. 